NASA Technical Memorandum 100413

\title{
X-29A Forward-Swept-Wing Flight Research Program Status
}

\section{Gary A. Trippensee and David P. Lux}

\author{
(MASA-TH-1004 13) X-29A FCBNAED-SWEPT-TIMG \$88-17644 \\ FIIGHT BESEACH PEOGRAE STATCS (NASA) $11 \mathrm{p}$ \\ CSCI $01 \mathrm{C}$

$\begin{array}{ll}\text { G.nclas } \\ \text { G3/05 } & 0124737\end{array}$

November 1987

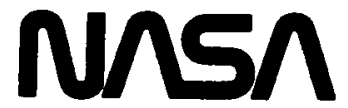

National Aeronautics and

Space Administration 
NASA Technical Memorandum 100413

\section{X-29A Forward-Swept-Wing Flight Research Program Status}

Gary A. Trippensee and David P. Lux

Ames Research Center, Dryden Flight Research Facility, Edwards, California

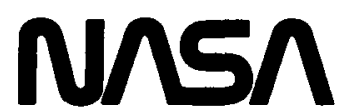

National Aeronautics and

Space Administration

Ames Research Center

Dryden Flight Research Facility

Edwards, California 93523-5000 


\title{
X-29A Forward-Swept-Wing Flight Research Program Status
}

\author{
Gary A. Trippensee \\ David P. Lux \\ NASA Ames Research Center \\ Dryden Flight Research Facility \\ Edwards, California \\ U.S.A.
}

\section{ABSTRACT}

The $\mathrm{X}-29 \mathrm{~A}$ aircraft is a fascinating combination of integrated technologies incorporated into a unique research aircraft. The X-29A program is a multiple-agency program with management and other responsibilities divided among the National Aeronautics and Space Administration (NASA), the Defense Advanced Research Projects Agency (DARPA), the U.S. Air Force, and the Grumman Corporation. This paper presents an overview of the recently completed X-29A flight research program, the objectives achieved to date, and a discussion of the future of the flight research program.

Also discussed are the flight test approach expanding the envelope, typical flight maneuvers performed, X-29A program accomplishments, lessons learned for the Number One aircraft, and future plans with the Number Two aircraft. A schedule for both the Number One and Number Two aircraft is presented. A description of the unique technologies incorporated into the X-29A aircraft is given, along with descriptions of the onboard instrumentation system.

The X-29A aircraft research program has proven highly successful. Using high fly rates from a very reliable experimental aircraft, the program has consistently met or exceeded its design and research goals.

THE ADVANTAGES OF THE FORWARD-SWEPTWING (FSW) design have been recognized since World War II, with Germany taking the most active role in producing several forward-swept-wing aircraft designs. Germany's first design was the Junkers JU287 Bomber and the most recent was the Hansa Business Jet. Ilowever, until composite materials became readily available in the early 1970 s, the forward-swept-wing design suffered from weight penalties in utilizing the conventional aluminum structure. This is particularly true of aircraft requirements for supersonic speeds.

In the 1970 s, Lt. Col. Norris Krone, while working on a doctoral dissertation at the University of Maryland, proposed the use of composite materials to construct a forwardswept-wing technology demonstrator aircraft. Defense Advanced Research Projects Agency (DARPA) became interested in this concept, and sponsored various design stud- ies to determine the feasibility of building and flight testing a forward-swept-wing aircraft utilizing composite wing structure techniques. Results of these studies were favorable, and full-scale design and fabrication plans commenced. The design studies indicated the following advantages of the forward-swept-wing design (as opposed to an aft-swept design) should be obtainable:

1. 10 to 20 percent less drag,

2. smaller engine and lower fuel consumption, and

3. 5 to 25 percent lower aircraft weight.

All these advantages, if proven, would result in a lighter, less costly aircraft for a given mission.

During the preliminary design studies, DARPA stressed the incorporation of other technologies into the aircraft to maximize the return on investment for any new flight test vehicle. These additional technologies, although highly synergistic with the FSW design, could also be used in comparable aft-swept-wing aircraft.

The Grumman Corporation became the prime contractor, building two aircraft that were designated X-29^ (Fig. 1).

\section{PROGRAM OBJECTIVES AND GOALS}

The simple overall objectives of the X-29A project were twofold. The first objective was to flight-demonstrate the validity of the FSW concept. The X-29A configuration was the first FSW supersonic design presenting totally new flight test challenges. The related technologies incorporated into the design were also to be flight-demonstrated. The second objective of the X-29A project was to produce an FSW aircraft data base providing viable design options for future aircraft.

The goal of the X-29A flight program was to complete the full flight envelope expansion tests by autumn of 1986 . This goal was accomplished on November 19, 1986, when the flight envelope was completely validated after 87 flights. 


\section{PROGRAM SCHEDULE}

The X-29A program has been active for a number of years, as shown in Fig. 2. The FSW feasibility studies began at DARPA in 1978, and continued into 1980. The Grumman Corporation started preliminary design in 1979. The final design and fabrication was a 4-year effort, starting in mid-1981 and continuing into early 1985 . The Number One aircraft first flew in December 1984.

The aircraft's initial flights were performed within a limited envelope because a constant-gain backup analog reversion flight control system (FCS) was initially designed for the aircraft. The full flight envelope FCS was installed in the aircraft in autumn of 1985 . Though the full flight envelope evaluation of the X-29A aircraft was completed on November 19, 1986, some envelope "cleanup" work and a U.S. Navy flight evaluation continued until the Number One aircraft was put into layup in early 1987 for the installation of a fully calibrated General Electric F404-400 engine.

A follow-on flight research program is planned through summer of 1988. During this time, the Number Two aircraft will be prepared by Grumman for a high-angle-of-attack (AOA), slow-speed flight program. The Number Two aircraft should begin its flight program in 1989 .

\section{PROGRAM MANAGEMENT}

DARPA contracted with the Grumman Corporation to build two aircraft using the U.S. Air Force Aeronautical Systems Division (ASD) as its agent. At the same time, DARPA arranged to have the Dryden Flight Research Facility of NASA Ames Research Center (Ames-Dryden) act as the responsible X-29A test organization. The Air Force Flight Test Center (AFFTC) at Edwards Air Force Base and Grumman continue to provide flight test support. However, in autumn of 1986, DARPA assumed a less active role and the U.S. Air Force took over as the governmental lead and responsible overall program manager, with NASA AmesDryden continuing in its role of responsible test organization (RTO).

\section{TECHNOLOGIES INCORPORATED INTO THE X-29A}

The X-29A aircraft was built to demonstrate forwardswept-wing technology. This, however, is not the only technology incorporated into the aircraft. These technologies include

1. relaxed static stability,

2. digital fly-by-wire flight control system,

3. aeroelastically tailored composite wings,

4. thin supercritical airfoil,
5. three-surface pitch control,

6. discrete variable-camber wing flaperons, and

7. full-authority close-coupled canards.

Each of these additional technologies works synergistically to enhance the capabilities of the X-29A. A brief discussion of each of these technologies follows.

The X-29A was designed to maximize sustained maneuvering performance at Mach 0.90 at $30,000 \mathrm{ft}$ altitude. At this condition, forward-swept-wing technology offers a reduction in drag over conventional aft-swept-wing designs with the same shock angle on the wing. This reduction in drag is due to the lower leading edge sweep of the forwardswept-wing configuration. This lower leading edge sweep allows more overall lift to be carried on the lower surface of the wing. This means that the pressure on the wing upper surface can be slightly more positive, causing a weaker shock wave, which results in less wave drag.

Relaxed static stability on the X-29A aircraft is due to the closely coupled canard configuration. These two technologies work together to maximize the overall lift distribution of the aircraft. With relaxed static stability the canard has a positive load in order to balance the aircraft. This load is carried in such a way as to obtain an optimum overall load distribution, minimizing the sum of profile plus induced drag. By optimizing the X-29A configuration this way, the resulting static margins give stability levels of -35 percent at low speed and -27 percent at the Mach 0.90 design point. This has been verified by both wind tunnel and flight test data.

The digital fly-by-wire flight control system is what makes all the technologies of the X-29A work together. The digital flight control system is used to give the X-29A its artificial stability and controllability, allowing the pilot to fly the aircraft. The X-29A control system is a triply redundant digital system with each of the flight computers having an analog backup computer running in parallel. Each computer is fed data from its own set of sensors with an intercom system between them, allowing them to perform comparisons and signal selection functions. This assures that the three channel commands sent to the aircraft actuators will be identical.

The flight control system utilizes three different major modes. The automatic camber control (ACC) mode automatically schedules the wing flaperons, canards, and strake flaps for the minimum drag at any point in the flight envelope. The manual camber control (MCC) mode, which is basically a flight test mode, is used to gather aerodynamic data with the flaperons fixed at designated positions. The analog reversion (AR) mode is the analog backup to the normal digital operation of the flight control system.

As has been stated, forward sweep offers the potential for large drag reduction in the transonic flight regime. However, there is no aircraft with forward sweep other than 
the X-29A currently flying transonically. This is because of a phenomena known as structural divergence. Structural divergence is caused by bend-pitch coupling, due to the forward sweep of the wing. As the wing bends under load the wing tip tends to pitch up, causing more load and repeating the cycle until the loads exceed the structural restoring forces of the wing. At this point the wing literally is ripped from the fuselage. The only way to avoid this in the past was to build a wing extremely heavy in order to make it strong enough to push the divergence speed outside the flight envelope. This was obviously impractical.

With the advent of modern composite materials, it was possible to build the stiffness and strength into the wing to allow forward sweep to be a viable design option with little or no weight penalty. This is called aeroelastic tailoring. This technology also allows the wing to be thin as well.

Thin supercritical airfoil technology has been incorporated into the $\mathrm{X}-29 \mathrm{~A}$ design to allow flight in the transonic flight regime with minimum drag. This technology was refined during the 1970s and is becoming commonplace on fighter-type aircraft currently flying.

Three-surface pitch control, as used on the X-29A, gives flexibility to the scheduling of the wing flaperons and canards to minimize aircraft trim drag when the flight control system is in the ACC mode throughout the flight envelope. This is accomplished through the use of the strake flap. The strake flap is also used during takeoff to reduce nosewheel lift-off speed, as well as at high angles of attack to give more nosedown pitching moment.

Discrete variable camber (Fig. 3) is used on the wing flaperons as a low-cost alternative to smooth variable camber, as on the AFTI/F-111 aircraft. Discrete variable camber allows a smooth upper surface wing contour at the $\mathrm{X}$ $29 \mathrm{~A}$ design condition with only minor penalties at the offdesign conditions. This also minimizes the trim drag of the aircraft, while optimizing the aerodynamic performance of the wing. Discrete variable camber is also used supersonically to minimize wave drag.

\section{KEY AIRCRAFT CHARACTERISTICS}

The $\mathrm{X}-29 \mathrm{~A}$ is a relatively small jet aircraft. Its key features are presented in the following tabulation:

\begin{tabular}{ll}
\hline \hline Length & $48 \mathrm{ft}$ \\
Wingspan & $27 \mathrm{ft}$ \\
Height & $14 \mathrm{ft}$ \\
Empty weight & $13,000 \mathrm{lb}$ \\
Fuel capacity & $4000 \mathrm{lb}$ \\
Wing area & $185 \mathrm{ft}^{2}$ \\
Canard area & $37 \mathrm{ft}^{2}$ \\
Aspect ratio & 4.0 \\
Engine static thrust & $16,000 \mathrm{lb}$ \\
\hline \hline
\end{tabular}

Since this aircraft was designed strictly for research purposes and not as a prototype for a future production design, inflight refueling capability was not incorporated.

The aircraft is powered by a General Electric F404-GE400 in the 16,000 -lb thrust class. This engine is similar to engines used in U.S. Navy F-18 aircraft. In the interest of economy, "off-the-shelf" items were used whenever possible, and the X-29A utilizes a U.S. Air Force F-5A forebody and cockpit, and Air Force F-16 main landing gear, flight control actuations, and emergency power unit (EPU). Grumman designed the engine inlet.

\section{X-29A FLIGHT TEST INSTRUMENTATION}

Because of the nature of the X-29A mission, the aircraft is highly instrumented with almost 700 parameters measured in flight (Ref. 1). The types of sensors used are rate gyros, accelerometers, strain gages, aerodynamic pressure taps, temperature and pressure monitors, pitot-static monitors and control surface position indicators, and rate indicators. The data aquisition system utilizes both pulse code modulation (PCM) and constant-bandwidth frequency modulation (FM) for data encoding, and integrates instrumentation data with data from the 429 data bus onto a single PCM data stream, which is telemetered directly to the ground station.

The PCM system consists of five separate units, located remotely throughout the aircraft, operating at different frame rates asynchronously. Inputs from these PCM units and the data bus are merged (using an interleaver unit) into a single PCM stream.

Examples of instrumentation layout are shown in Figs. 4 to 6 . The structural dynamics instrumentation consists of accelerometers located in the forward fuselage, on the wing and canard tips, and on each of the flight control surfaces. This instrumentation was used to clear the aircraft for flutter throughout the flight envelope.

The static structures instrumentation (Fig. 4) consists of shear, bending, and torsion strain gages located at the root of the left and right wings, left and right canards, and at four stations on the left wing. Actuator loads on all control surfaces as well as stick and rudder pedal forces were also measured.

Pressure survey instrumentation is located on the lefthand wing, canard, and strake. This instrumentation consists of flush static pressure taps located in two rows on the canard, four rows on the wing, and one row on the strake.

$A$ rather unique part of the instrumentation system is the deflection measurement system (Fig. 6) located on the right-hand wing external to the aircraft. This system consists of 12 individual light-emitting diodes or targets that are focused on a diode array located in the fuselage side. The system pulses each of the targets individually, and the received impulses are input to the PCM system. This in- 
formation is later reduced to give wing bending and torsion information, which is used by the pressure survey and wing divergence experimenters.

\section{ENVELOPE EXPANSION APPROACH}

The envelope expansion approach used to flight-test the $\mathrm{X}-29 \mathrm{~A}$ aircraft is depicted in Fig. 7. The approach generally used was to work from the upper left-hand corner of the envelope to the lower right-hand corner. A target altitude was selected and expansion maneuvers were flown at progressively higher Mach numbers until a target dynamic pressure was reached. At that point the altitude was decreased to the next lower selected altitude along a constant dynamic pressure line where the expansion would continue. This was continued until the highest dynamic pressure points were reached, concluding the expansion.

Several special expansion points were conducted in an effort to identify a flaperon tab flutter mode that was predicted by the flutter analysis. These points are shown in the figure as those points outside the $1-\mathrm{g}, \mathrm{P}_{s}=0$ envelope. These points were reached by climbing to approximately $50,000 \mathrm{ft}$ altitude and diving into the points.

While this approach to the envelope expansion would seem rather conventional, by virtue of the highly integrated nature of the X-29A, this approach was quite challenging. The envelope had to be cleared simultaneously for flight controls, handling qualities, static structural loads, dynamic loads and aeroservoelasticity, aerodynamic stability and control, aircraft systems, and propulsion. This required developing special maneuver blocks that could be used by all the previously mentioned disciplines. These maneuver blocks, referred to as integrated test blocks 1 and 2 (ITB-1 and ITB-2) are defined in the following lists:

ITB-1-1-g flight envelope expansion maneuvers

1-min stabilized point and control raps

Longitudinal maneuver block

-Pitch doublet fast-slow (repeat)

-Stick rap

-Frequency sweep

Lateral block

-Roll-yaw doublet (repeat)

-Stick rap

-Frequency sweep

Directional block

-Yaw-roll doublet

-Pedal rap

ITB-2-performance flight evelope expansion maneuvers Wings-level sideslips

Roll-yaw doublets in sideslip

Partial-stick $0^{\circ}$ to $60^{\circ}$ rolls (left-right)

Full stick $360^{\circ}$ rolls (left-right)

Roll-pitch step inputs
Constant-altitude windup turn

Constant-thrust windup turn

Pushover-pullups

The first of these integrated test blocks, or ITB-1, was for clearing the $1-\mathrm{g}$ portion of the envelope. It consists of a 1 -min stabilized point, followed by control raps for the dynamics and aeroservoelasticity clearance. This is then followed by a longitudinal maneuver block, a lateral maneuver block, and a directional block. All maneuvers were used for flight control and aerodynamic stability and control clearance.

The second of the integrated test blocks, or ITB-2, was used to clear the maneuvering portion of the envelope. This test block consists of wings-level sideslips, roll-yaw doublets in sideslip, partial-stick $0^{\circ}$ to $60^{\circ}$ rolls (left-right), fullstick $360^{\circ}$ rolls (left-right), roll-pitch step inputs, constantaltitude windup turns, and pushover-pullups. This maneuver block cleared flight controls, aerodynamic stability and control, static structural loads, and propulsion.

Each of these maneuver blocks was performed for each expansion point. Typically an ITB-1 was performed first, followed by an ITB-2 at a lower Mach number. These integrated test blocks were also performed for expansion of the different flight control modes tested.

This expansion approach assured a thorough and safe expansion to be performed on a highly integrated aircraft.

\section{FLIGHT PROGRAM ACCOMPLISHMENTS}

With the successful completion of the envelope expansion phase, the X-29A design philosophy and technology performance predictions are now well documented. The correlation between design predictions and subsequent wind tunnel tests with flight results has been excellent. Flight performance of the aircraft has been consistently equal to or slightly better than predicted.

The design conditions of $30,000 \mathrm{ft}$ at Mach 0.9 and $30,000 \mathrm{ft}$ at Mach 1.2 have been documented. The reliability of the $\mathrm{X}-29 \mathrm{~A}$ design has allowed high fly rates at various phases of the program. The X-29A's highest fly rates were 4 flights per day, 7 flights per week, and 17 flights in one month. These rates set records for the maximum flights ever attained for a U.S. X-series aircraft. The aircraft accomplished a total of 110 flights as of July 1987.

The maximum flight conditions reached with the aircraft were altitudes up to $50,000 \mathrm{ft}$, Mach 1.47 , and normal load factor $N_{z}=5.7 \mathrm{~g}$.

\section{CONCLUSIONS AND LESSONS LEARNED}

The data base obtained during the X-29A flight program validates the FSW concept and its attendant tech- 
nologies that would result in a smaller, lighter, less costly aircraft, able to meet a given set of highly maneuverable aircraft goals.

Several "lessons learned" have emerged from the flight test program. The most significant of these lessons are the following:

1. Do not compromise the quality of instrumentation or the quantity of sensors. Even though the X-29A airframe and subsystem were very reliable, the instrumentation system required the largest amount of maintenance.

2. A collocated, hardware-in-the-loop simulation is necessary for safe and efficient flight test of this type of air vehicle.

3. Strip chart monitoring of traditional aircraft response parameters does not ensure safe envelope clearance for aircraft with highly relaxed static stability. Active, online loads and vehicle performance and flight, control analyses are required during the flight tests.

\section{FUTURE PLANS}

The Number One aircraft remains in a follow-on flight research program, which is planned to continue into the summer of 1988. The primary areas of interest in this follow-on phase are to evaluate several methods of calculating in-flight thrust, to evaluate several digital flight control improvements, and to address additional performance and agility issues.

The Number Two aircraft test program will begin after the aircraft arrives at Ames-Dryden in the summer of 1988. Since the thrust of the Number Two aircraft program is to evaluate the FSW configuration in the slow-speed, high-angle-of-attack region, initial flight tests of this aircraft will be flown to qualify the spin recovery parachute system and emergency power systems. Flights to angles of attack greater than $40^{\circ}$ are planned with the Number Two aircraft.

\section{NOMENCLATURE}

\begin{tabular}{|c|c|}
\hline $\mathrm{ACC}$ & automatic camber control \\
\hline AFFTC & Air Force Flight Test Center \\
\hline Ames-Dryden & $\begin{array}{l}\text { NASA Ames Research Center, Dryden } \\
\text { Flight Research Facility }\end{array}$ \\
\hline $\mathrm{AOA}$ & angle of attack \\
\hline AR & analog reversion \\
\hline ASD & $\begin{array}{l}\text { U.S. Air Force Aeronautical Systems } \\
\text { Division }\end{array}$ \\
\hline DARPA & $\begin{array}{l}\text { Defense Advanced Research Projects } \\
\text { Agency }\end{array}$ \\
\hline EPU & emergency power unit \\
\hline FCS & flight control system \\
\hline FDMS & flight deflection measurement system \\
\hline FM & frequency modulation \\
\hline FSW & forward-swept wing \\
\hline g & gravity \\
\hline ITB & integrated test block \\
\hline MCC & manual camber control \\
\hline NASA & $\begin{array}{l}\text { National Aeronautics and Space } \\
\text { Administration }\end{array}$ \\
\hline$N_{z}$ & normal load factor \\
\hline PCM & pulse code modulation \\
\hline$P_{\mathbf{s}}$ & specific excess thrust \\
\hline RTO & responsible test organization \\
\hline
\end{tabular}

\section{REFERENCE}

(1) Sefic, Walter J., and Maxwell, Cleo M., "X-29A Technology Demonstrator Flight Test Program Overview," NASA TM-86809, 1986.

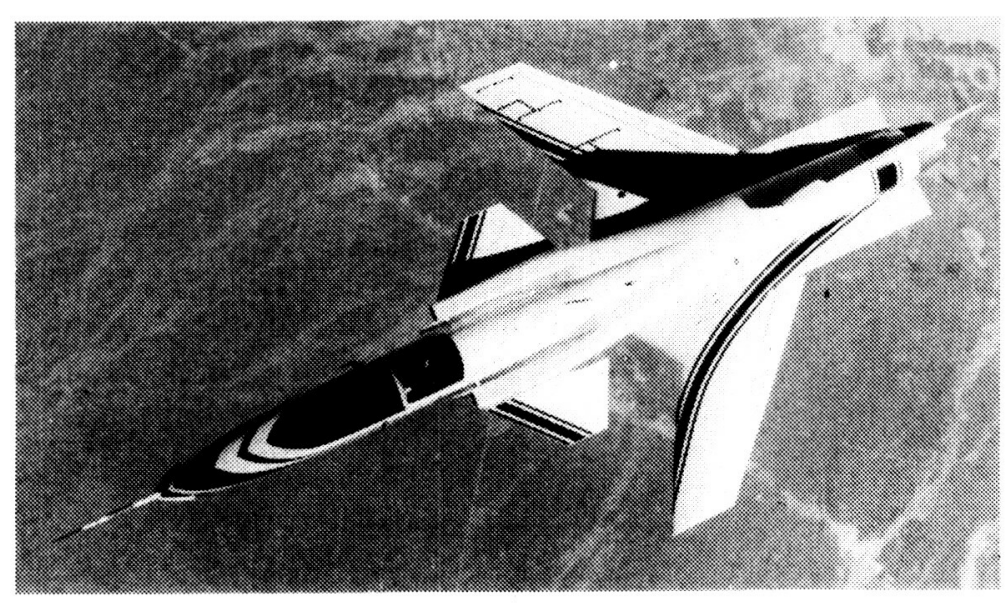

Figure 1. X-29A aircraft. 


\begin{tabular}{|l|l|l|l|l|l|l|l|l|l|l|l|l|}
\hline FY & 78 & 79 & 80 & 81 & 82 & 83 & 84 & 85 & 86 & 87 & 88 & 89 \\
\hline
\end{tabular}

FEASIBILITY STUDIES

PRELIM DESIGN

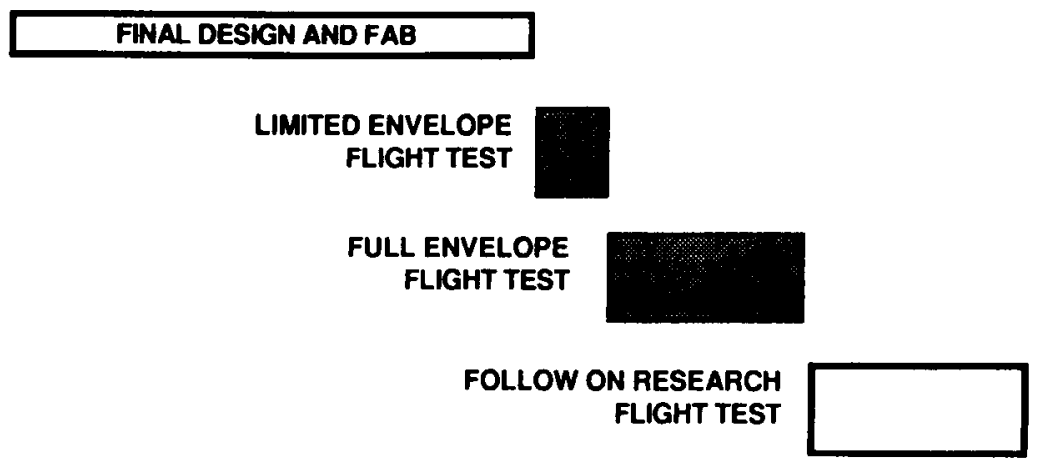

HIGH A-O-A RESEARCH

FLIGHT TEST

FIRST FLIGHT ANC 1

FIRST FLIGHT AC 2

Figure 2. X-29A program schedule.

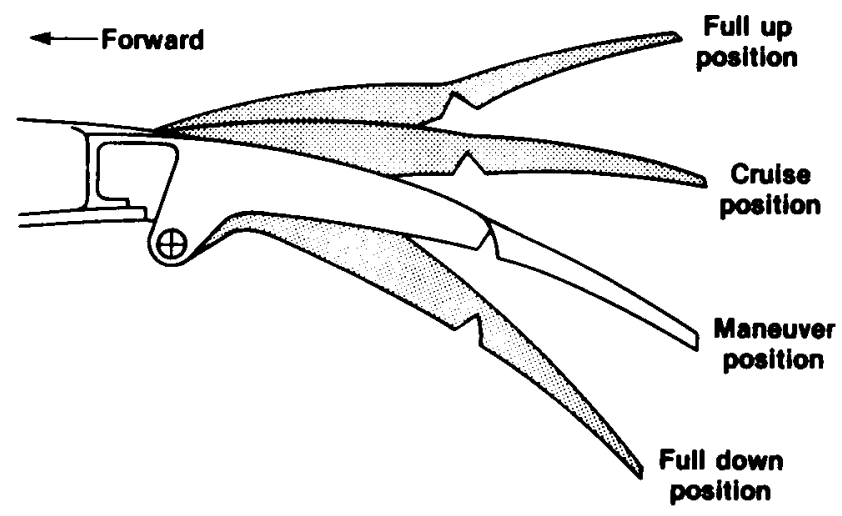

Figure 9. Discrete variable camber. 


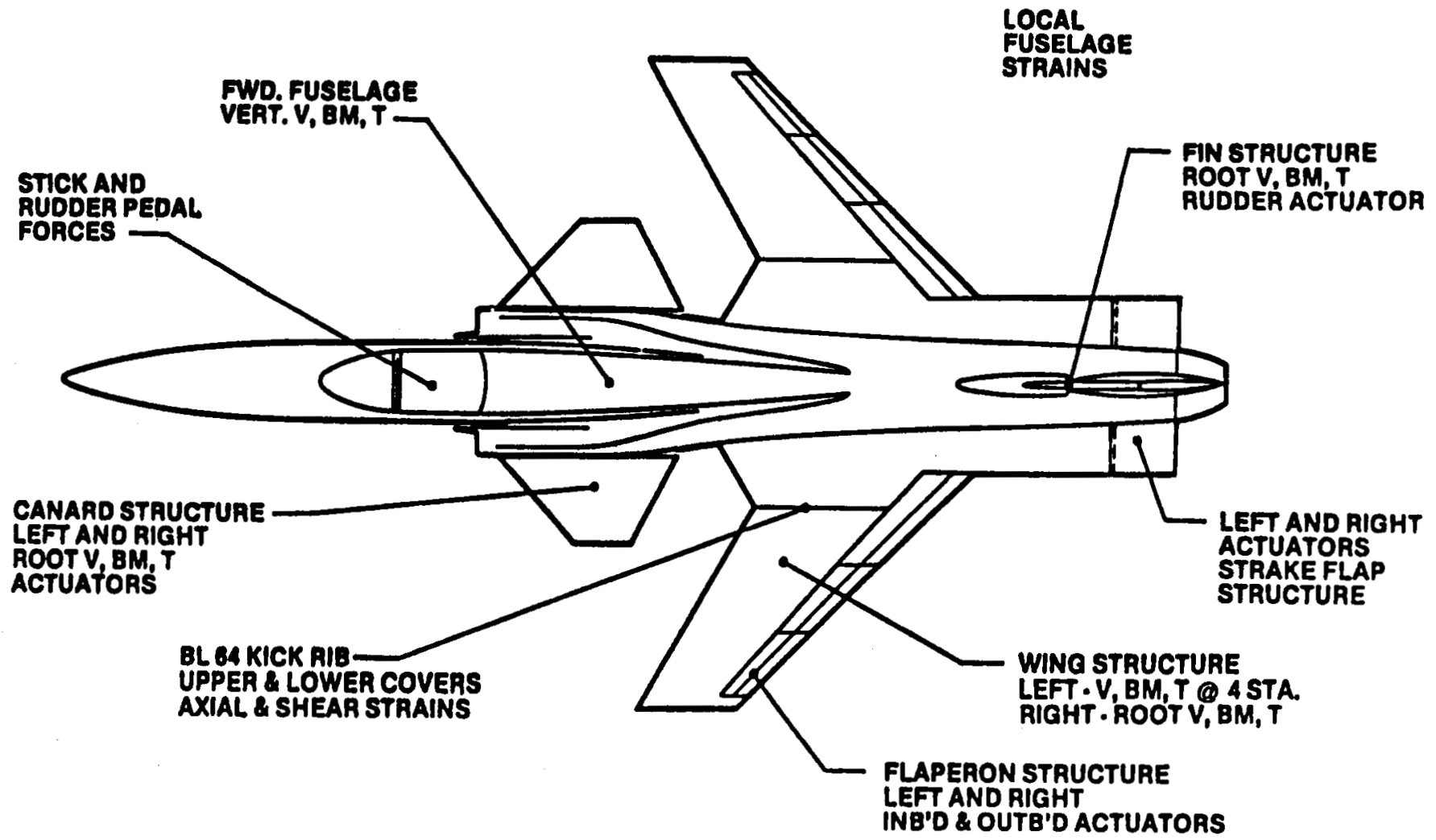

Figure 4. Structural loads instrumentation.

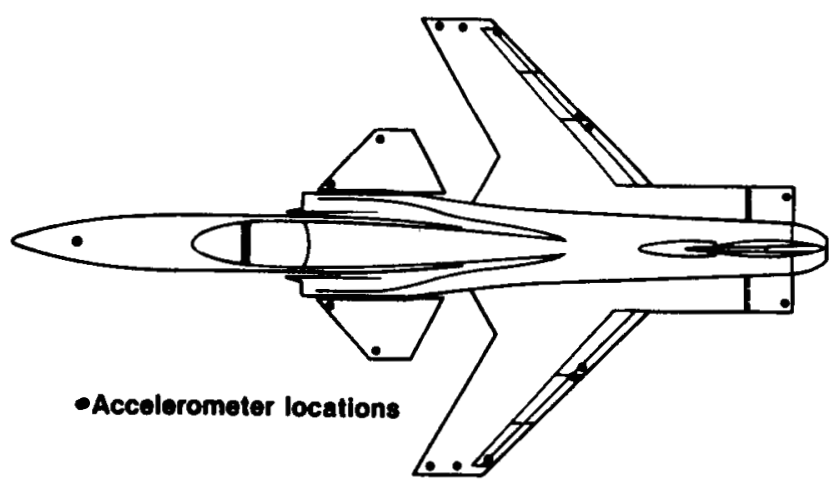

7171

Figure 5. Structural dynamics instrumentation. 


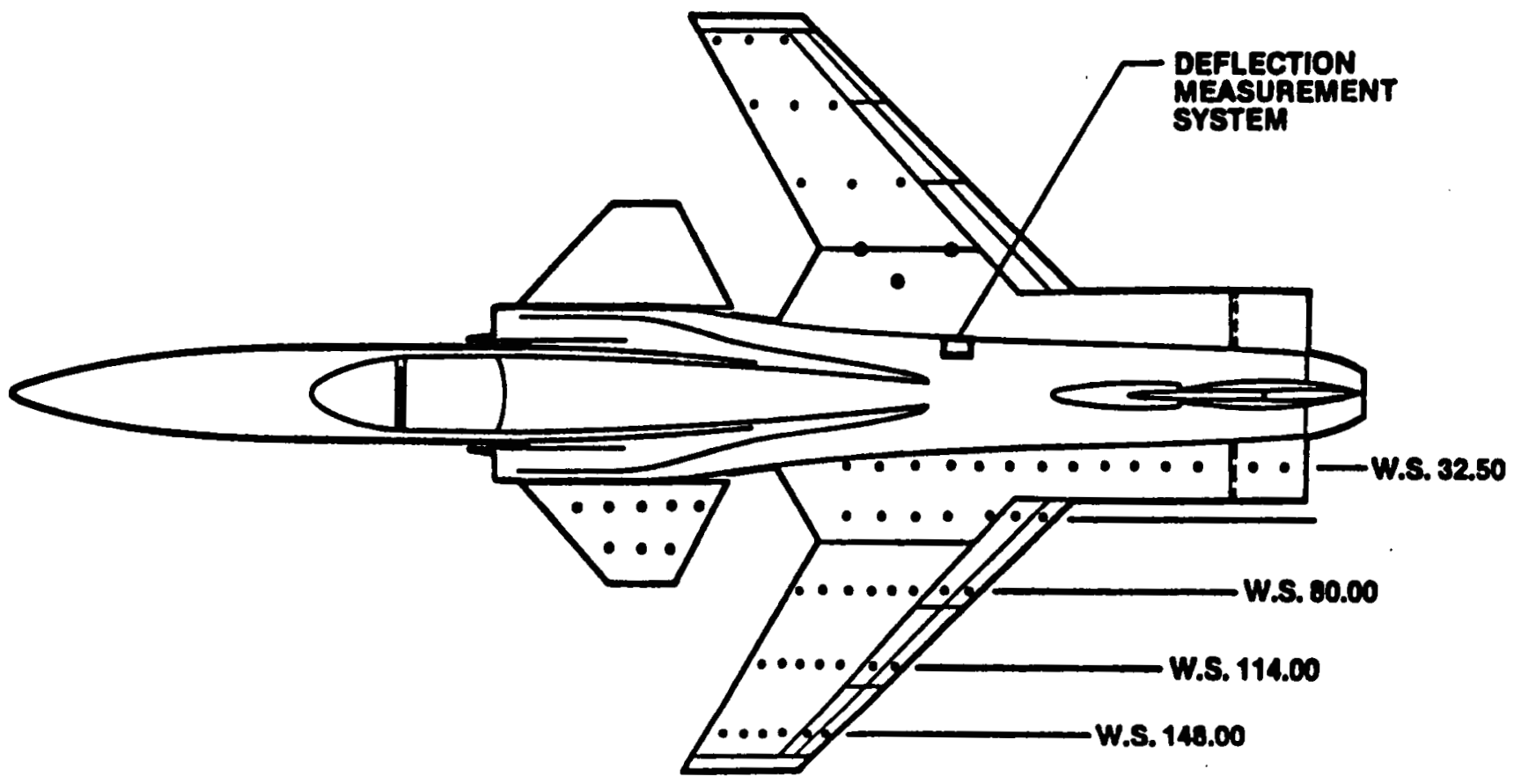

Figure 6. Pressure survey and optical deflection measurement system.

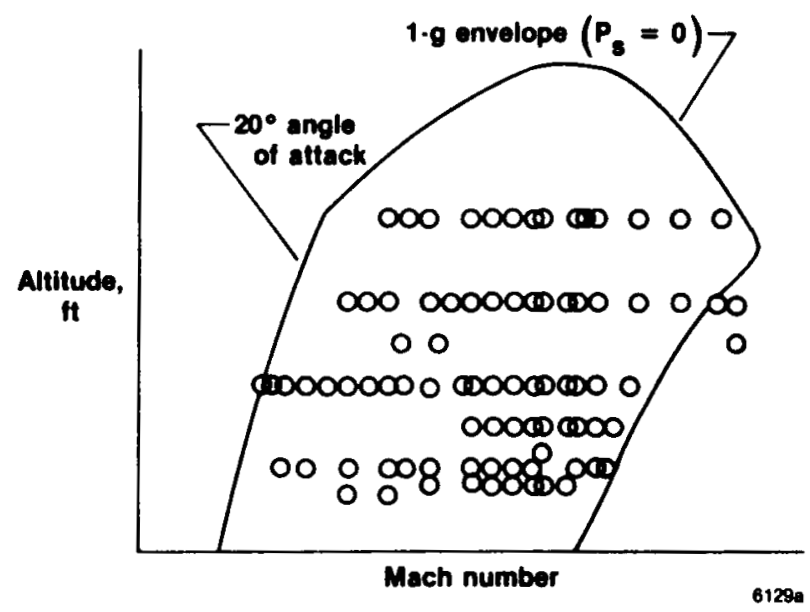

Figure 7. Flight envelope expansion approach. 


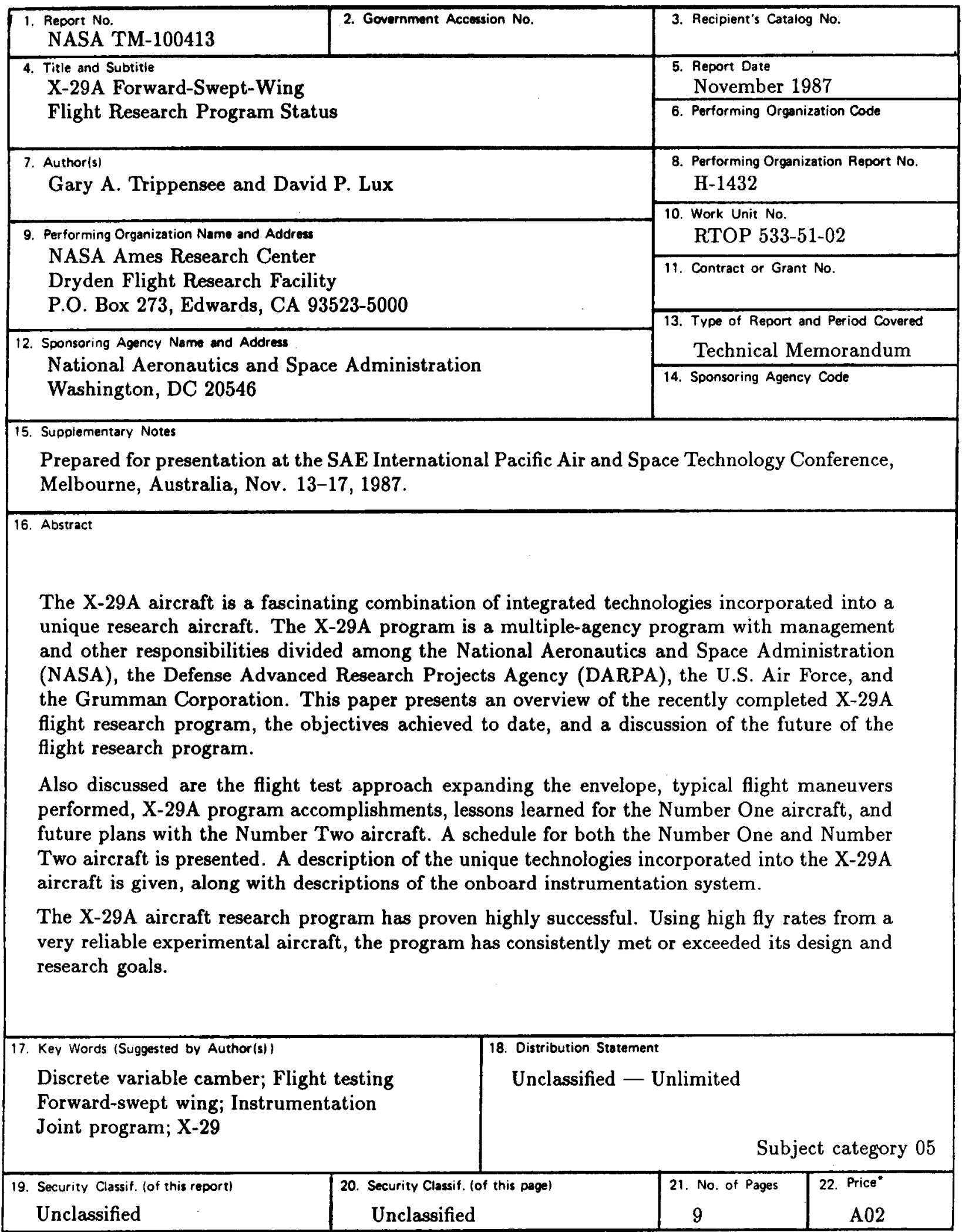

*For sale by the National Technical Information Service, Springfield, Virginia 22161. 